\title{
Numerical simulation of tropospheric injection of biomass burning products by pyro-thermal plumes
}

\author{
C. Rio $^{1}$, F. Hourdin ${ }^{1}$, and A. Chédin ${ }^{2}$ \\ ${ }^{1}$ Laboratoire de Météorologie Dynamique, UMR8539, CNRS/IPSL, UPMC, 75252 Paris, France \\ ${ }^{2}$ Laboratoire de Météorologie Dynamique, UMR8539, CNRS/IPSL, Ecole Polytechnique, 91128 Palaiseau, France
}

Received: 17 July 2009 - Published in Atmos. Chem. Phys. Discuss.: 10 September 2009

Revised: 23 February 2010 - Accepted: 15 March 2010 - Published: 16 April 2010

\begin{abstract}
The thermal plume model, a mass-flux scheme originally developed to represent the vertical transport by convective structures within the boundary layer, is adapted to the representation of plumes generated by fires, with the aim of estimating the height at which fire emissions are actually injected in the atmosphere. The parameterization, which takes into account the excess of near surface temperature induced by fires and the mixing between convective plumes and environmental air, is first evaluated on two well-documented fires. Simulations over Southern Africa performed with the general circulation model LMDZ over one month show that the $\mathrm{CO}_{2}$ can be injected far above the boundary layer height, leading to a daily excess of $\mathrm{CO}_{2}$ in the mid-troposphere of an order of 2 ppmv. These results agree with satellite retrievals of a diurnal cycle of $\mathrm{CO}_{2}$ in the free troposphere over regions affected by biomass burning in the Tropics.
\end{abstract}

\section{Introduction}

Biomass burning is a significant source for a number of atmospheric trace species. Because a fire is thermodynamically active, the vertical distribution of fire emissions depends on both its characteristics and on the meteorological environment (Kahn et al., 2007). The representation of the vertical transport of emissions above fires is a concern for the purpose of global modelling of the atmospheric composition. However, it is rarely taken into account in General

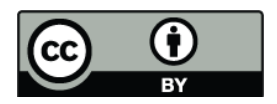

Correspondence to: C. Rio (catherine.rio@lmd.jussieu.fr)
Circulation Models. Here, we propose a parameterization for the convective plumes generated by the excess of buoyancy associated with biomass burning and use it to simulate the transport of $\mathrm{CO}_{2}$ from fires over Southern Africa. This study was initially motivated by satellite retrievals from Chédin et al. (2005) suggesting a strong diurnal cycle of carbon dioxide concentration over regions affected by biomass burning, well above the planetary boundary layer. Chédin et al. (2008) show that the amplitude of this so-called Daily Tropospheric Excess (hereafter DTE) of $\mathrm{CO}_{2}$ is highly correlated with Van der Werf et al. (2006) estimates of the $\mathrm{CO}_{2}$ emissions from biomass burning. The retrieval being sensitive to the mean $\mathrm{CO}_{2}$ concentration in the mid-to-upper part of the troposphere, Chédin et al. (2005) and Chédin et al. (2008) allocate this observed excess of $\mathrm{CO}_{2}$ to a rapid uplift during the day of fire emissions - which peaks around 15:00 LT (Giglio, 2007) - to the upper troposphere. As there are no meteorological convective systems over those regions at that time of the year, which could transport fire emissions to the upper troposphere at a daily scale, the question we try to answer here is whether the vertical transport of fire emissions due to fire induced convection, so called "pyroconvection", may explain this observed diurnal cycle.

Plumes generated by an excess of temperature induced by biomass burning have already been observed to reach the stratosphere in mid and high latitudes (Fromm and Servranckx, 2003; Jost and al., 2004). Such plumes are associated with "pyro-clouds", resulting from condensation of water vapour inside the plume. The conjunction of several factors can explain such a high penetration of fire plumes: the density of fuel available (dense forests), the weak inversion at the top of the boundary layer and the occurrence of meteorological convective systems. During the dry season,

Published by Copernicus Publications on behalf of the European Geosciences Union. 


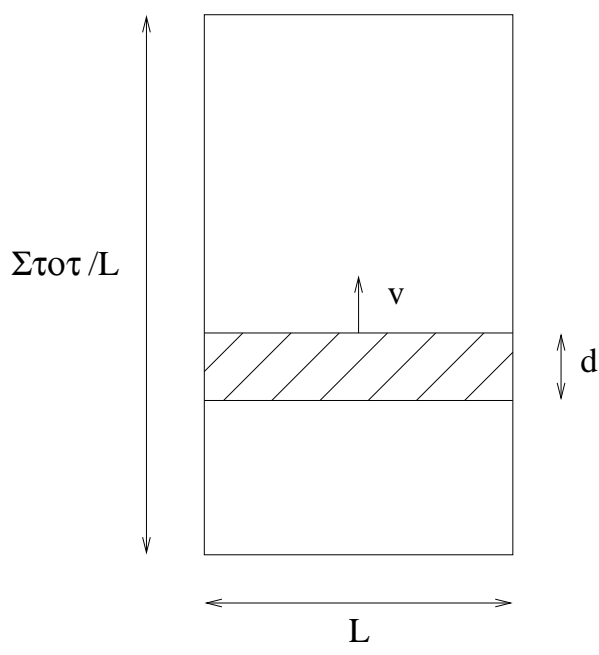

Fig. 1. Schematic view of the propagation of an idealized fire. The rectangular front of width $L$ and depth $d$ propagates at speed $v$.

conditions can be less favourable in some regions of the Tropics, where atmospheric conditions can be dry and stable with a strong inversion at the top of the boundary layer, and predominant vegetation is woodlands and grasslands. Even if there are large deforestation areas in South Africa as in South America, high pyro-clouds are rarely referenced in Southern Africa, where pyro-plumes are mostly reported to stay confined within the boundary layer. However, Coheur et al. (2007) report emissions from a young plume in the upper troposphere over Tanzania. Freitas et al. (2007) propose a model of pyro-convection used in combination with a regional circulation model. In the latter study, the model for pyro-convection is used to deduce from fire characteristics and synoptic conditions a minimal and a maximal injection height, between which gases are then uniformely emitted and transported by the 3-D model. They simulate maximal injection heights of an order of $10 \mathrm{~km}$ in Southern America and of $7 \mathrm{~km}$ in Southern Africa. Using the same model, Guan et al. (2008) show that the representation of pyro-convection is necessary to reproduce the observed concentration of $\mathrm{CO}$ over South Africa during SAFARI 2000 by lifting CO directly in the mid-troposphere. Those recent studies confirm that emissions from biomass burning can be injected directly above the boundary layer, even in Southern Africa during the dry season. However, refined observations of fire plumes and emissions are still missing at regional scale. Occasionaly, such observations are performed in the framework of field campaign, like SAFARI in 2000 over South Africa or more recently the AMMA (African Monsoon Multidisciplinary Analysis) program. Chédin et al. (2009) have recently refined their analysis of satellite-retrieved $\mathrm{CO}_{2}$ columns over Southern Africa, confirming the tight relationship between the DTE signal and $\mathrm{CO}_{2}$ emissions from biomass burning at regional scale.
In order to study the impact of pyro-convection on the $\mathrm{CO}_{2}$ distribution at global scale, we adapted a mass-flux scheme originally developed to represent convective processes in the atmospheric boundary layer, the thermal plume model (Hourdin et al., 2002; Rio and Hourdin, 2008), to the representation of convective plumes induced by biomass burning. The "pyro-thermal plume model" presented here computes the vertical profiles of temperature, humidity and emitted gases along pyro-plumes given environmental conditions, $\mathrm{CO}_{2}$ and heat flux released. The model thus provides the vertical distribution of the effective injection of biomass burning products in the atmosphere.

This paper is organized as follows. The development of the "pyro-thermal" plume model from the existing thermal plume model is first described in Sect. 2. The pyro-thermal plume model is then qualitatively evaluated on two welldocumented fires either from observations (Stocks et al., 1996) or from previous studies performed with explicit simulations of fire plumes (Trentmann et al., 2006; Luderer et al., 2006). The impact of pyro-convection on the $\mathrm{CO}_{2}$ distribution at regional scale is investigated in Sect. 4, using the General Circulation Model LMDZ (Hourdin et al., 2006), focusing on July over Southern Africa. Conclusions are drawn in Sect. 5 .

\section{The pyro-thermal plume model}

\subsection{Idealization of a fire}

In the pyro-thermal plume model, a fire is characterized by two parameters: an instantaneous active burning area and an associated heat flux released. For the sake of simplicity, we consider a rectangular active fire of width $L$, depth $d$ and surface $S=L d$ as illustrated in Fig. 1. The back and front of the fire are assumed to propagate at the same constant velocity $v$ so that the total area burned $\Sigma_{\text {tot }}$ during the lifetime $T$ of the fire is $\Sigma_{\mathrm{tot}}=L v T$. The heat released by combustion $\left(E\right.$ in $\mathrm{J} \mathrm{m}^{-2}$ ) after the passing of the active fire is the product of the density of biomass burned $\omega$ (in $\mathrm{kg} \mathrm{m}^{-2}$ ) by the fuel low heat of combustion $C$ (Byram, 1959): $E=C \omega$, with $C \approx 17781 \mathrm{~kJ} \mathrm{~kg}^{-1}$ (Stocks and Flannigan, 1987). The averaged heat flux $F$ (in $\mathrm{J} \mathrm{s}^{-1} \mathrm{~m}^{-2}$ ) released by the active part of the fire is related to $E$ by:

$\mathrm{SFT}=\Sigma_{\mathrm{tot}} E$

so that we have:

$F=\frac{\Sigma_{\mathrm{tot}} E}{S T}=\frac{E v}{d}$

The power of the fire front $I$ (in $\mathrm{kW} \mathrm{m}^{-1}$ ) can be computed from:

$I=F d=C \omega v$ 


\subsection{Model equations}

The parameterization for pyro-convection is adapted from the "thermal plume model" developed initially to represent coherent structures of the convective boundary layer (Hourdin et al., 2002; Rio and Hourdin, 2008). The thermal plume model is a mass-flux scheme, which computes vertical profiles of water, temperature and velocity inside a plume generated by a buoyancy excess near the surface, given some assumptions about the geometry of the plume and the mixing of air between the plume and its environment, referred to as lateral entrainment and detrainment. Each atmospheric column is divided into a mean ascending thermal plume of mass flux $f=\alpha \rho w_{u}$ (where $\rho$ is the air density, $\alpha$ the fraction of a grid cell covered by the plume and $w_{u}$ the vertical velocity), and a compensating subsidence in the environment of mass-flux $-f$ as illustrated in Fig. 2.

The conservation of mass relates the vertical variation of $f$ to the entrainment rate of air mass inside the plume $e$ and the detrainment rate of air mass from the plume $d$ :

$\frac{\partial f}{\partial z}=e-d$

Assuming stationarity, the plume properties are computed from:

$\frac{\partial f \Psi_{u}}{\partial z}=e \Psi_{e}-d \Psi_{u}$

where $\psi$ is a conserved quantity and subscript " $u$ " stands for the updraft and " $e$ " for the environment. As in classical mass-flux parameterizations of deep convection, the assumption is made that environmental mean values are equal to large scale values $\left(\psi_{e}=\psi\right)$. This conservation equation is applied to total water $r_{t}$, liquid potential temperature $\theta_{l}$ and $\mathrm{CO}_{2}$ concentration. The plume vertical velocity is computed from the conservation of momentum in stationary and frictionless conditions:

$$
\frac{\partial f w_{u}}{\partial z}=-d w_{u}+\alpha \rho \gamma
$$

where

$\gamma=g \frac{\theta_{v u}-\theta_{v e}}{\theta_{v e}}$

is the plume buoyancy, $\theta_{v}$ being the virtual potential temperature and $g$ the gravity acceleration.

To close the system of equations, once mixing rates have be specified, an equation for the mass-flux at the base of the plume is still missing. In the original thermal plume model, the closure relates the maximal velocity inside the plume to the horizontal convergence of air in the surface layer. Here, the closure is modified to compute the mass-flux at the base of the plume from fire characteristics as explained in the following section. Note that there is no sophisticated representation of microphysics in this model, which aims to represent

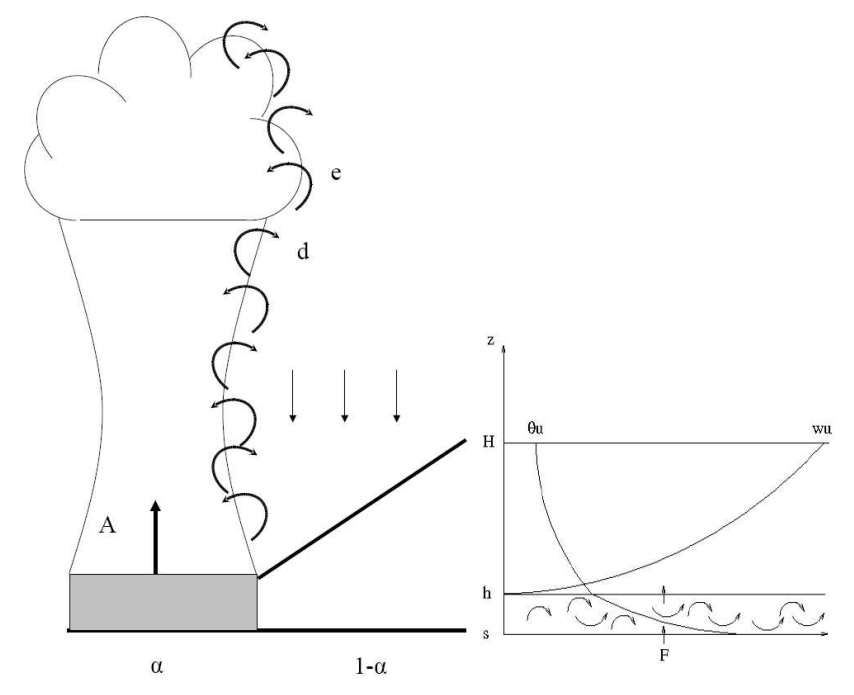

Fig. 2. Schematic view of the pyro-thermal generated by a fire (left) and zoom on the feed layer (right): diffusion is dominant in a layer of depth $h$ near surface while transport by thermals is dominant above. The plume covers a fraction $\alpha$ of the grid cell and is generated by the excess of temperature induced by fires leading to a vertical velocity $w_{u}$, a potential temperature $\theta_{u}$ and a mass-flux $A$ at the top of the feed layer of height $H$. The plume mixes with environmental air at each level at rates $e$ and $d$.

the dynamics of pyro-convection at a first order. The water is instantaneously condensed when supersaturation occurs, and the condensed water in transported within the plume.

\subsection{Initialization of the pyro-thermal}

The pyro-plume is initialized in the first model layer, the top of which is located in our simulations around $H=70 \mathrm{~m}$. Turbulence in the first model layer is illustrated in Fig. 2. Smallscale turbulence and coherent structures are both active in that layer. We assume that below an height $h$ diffusion is dominant, while above $h$ the transport becomes more organized and is mostly carried out by convective cells. Below $h$, we assume a flux of the form:

$\rho \overline{w^{\prime} \theta^{\prime}}=\frac{K\left(\theta_{s}-\theta_{h}\right)}{h}$

where $K$ is a diffusion coefficient and $\theta_{s}$ the surface potential temperature. Above $h$, the flux is computed from plume properties, which are initiated by the temperature excess and the positive vertical velocity induced by fires in layer $H$, the computation of which is explained in the following.

In layer $H$, we assume that the area covered by the plume does not vary on the vertical and that the virtual potential temperature in the environment of the plume is homogeneous. At height $H$, the heat flux $F$ released by the fire is $F=\rho C_{p} w_{u} \theta_{0}^{\prime}$, where $\theta_{0}^{\prime}$ is the excess of $\theta_{v}$ inside the plume 
and $C_{p}$ is the specific heat of air. In the absence of detrainment, the vertical component of the momentum equation (Eq. 6) is:

$\frac{\partial f w_{u}}{\partial z}=g \alpha \rho \frac{\theta_{0}^{\prime}}{\theta_{v e}}$

As the surface covered by the plume is constant in layer $H$, Eq. (9) becomes (neglecting the variations of $\rho$ ):

$\frac{\partial w_{u}^{2}}{\partial z}=g \frac{\theta_{0}^{\prime}}{\theta_{v e}}=g \frac{F}{\rho C_{p} w_{u} \theta_{v e}}$

Thus

$\frac{2}{3} \frac{\partial w_{u}^{3}}{\partial z}=\frac{g F}{\rho C_{p} \theta_{v e}}$

from which we deduce the vertical velocity at $H$ :

$w_{u}(H)=w_{0}=\left(\frac{3 g F H}{2 \rho C_{p} \theta_{v e}}\right)^{1 / 3}$

The temperature excess $\theta_{0}^{\prime}$ induced by the fire in layer $H$ is finally:

$\theta_{0}^{\prime}=\frac{F}{\rho C_{p} w_{0}}=\left(2 \frac{\left(\frac{F}{\rho C_{p}}\right)^{2} \theta_{v e}}{3 g H}\right)^{1 / 3}$

We find that $w_{0}$ scales with $F^{1 / 3}$ and $\theta_{0}^{\prime}$ with $F^{2 / 3}$, a dependence also established by Freitas et al. (2007).

The plume is thus initialized at the top of the first model layer by $\theta^{\prime}{ }_{0}$ from Eq. (13) and a mass-flux $f=\alpha \rho w_{0}$ with $\alpha=S / S_{m}$ where $S_{m}$ is the area of the model grid cell. Note that this initialization does not depend on the $K$ coefficient or $h$, which thus not need to be specified in the framework of this study. Those coefficients are related to the surface temperature excess $\theta_{s}-\theta_{h}$, which thus could be deduced from $\theta^{\prime}{ }_{0}$ making further assumptions on $K$ and $h$.

\subsection{Specification of mixing rates}

Due to boundary layer turbulence, potential temperature in the environment of the fire is well-mixed above the surface layer, up to a specific height that corresponds to the minimum of virtual potential temperature flux. In this mixed layer, we assume that the lateral entrainment of environmental air exactly compensates the narrowing of the plume coverage due to acceleration (as $\alpha=\frac{f}{\rho w_{u}}$ ). This would lead to a fraction covered by the plume independent of height in the absence of detrainment. This large convergence of air explains the fast decrease of temperature with height commonly observed above fires. If we suppose that $\alpha \rho$ rather than $\alpha$ is constant within the mixed layer, in the absence of detrainment, Eq. (6) leads to:

$\alpha \rho \frac{\partial w_{u}^{2}}{\partial z}=\alpha \rho \gamma$
The entrainment needed to keep the fraction constant in the mixed layer is thus:

$e=\frac{\partial f}{\partial z}=\alpha \rho \frac{\partial w_{u}}{\partial z}=\frac{\alpha \rho}{2 w_{u}} \frac{\partial w_{u}^{2}}{\partial z}=\frac{\alpha \rho}{2 w_{u}} \gamma$

Detrainment in the mixed layer is specified considering that the plume is eroded with a mixing length $\lambda$ :

$d=\frac{\partial}{\partial z}\left(\frac{\alpha \rho w_{u} \sqrt{\lambda z}}{l}\right)$

where $l$ is a characteristic length of the fire geometry, defined as $\sqrt{(S)}$. We take $\lambda=30 \mathrm{~m}$ as in the original version of the scheme.

Above the mixed layer, and inside pyro-clouds, entrainment and detrainment rates are specified for simplicity as constant fractions of the mass-flux, a classical formulation derived from explicit simulations of shallow convection (Siebesma and Holtslag, 1996):

$d=\delta f$

$e=\epsilon f$

In the thermal plume model of Rio and Hourdin (2008), $\delta=0.002 \mathrm{~m}^{-1}$ and $\epsilon=0.0008 \mathrm{~m}^{-1}$, values deduced from simulations of shallow cumulus. However, mixing rates should probably be an order of magnitude lower for deep than for shallow convection (Tiedtke, 1989; Siebesma and Holtslag, 1996). As pyro-convection can be either shallow or deep, we make $\epsilon$ and $\delta$ inversely proportional to a characteristic dimension of the plume, taken as $\sqrt{(} S)$, so that the larger the plume, the smaller the relative mixing. Detrainment is larger than entrainment and we have $\epsilon=\beta \delta$ with $\delta=1 / \sqrt{(} S)$ and $\beta=0.4$.

\section{Evaluation of the scheme on two well-documented fires}

For evaluation of the pyro-thermal plume model we first simulate pyro-plumes generated by two well-documented fires: a boreal forest fire in Canada and a savanna fire in South Africa.

\subsection{The Chisholm fire in Canada}

The Chisholm fire occurred between the 23 and the 29 May 2001 in Canada and burned an area of 100000 ha (ASRD, 2001). On the 28 May a pyro-cloud was observed above the fire and emissions were retrieved above the tropopause, in the stratosphere (Fromm and Servranckx, 2003), located at $12 \mathrm{~km}$ in this region. Environmental conditions issued from ERA40 reanalysis at fire location $(55 \mathrm{~N} / 114 \mathrm{~W})$ the 28 May 2001 at 16:30 LT are illustrated in Fig. 3. The mixed layer height is estimated to be approximately $2500 \mathrm{~m}$. 

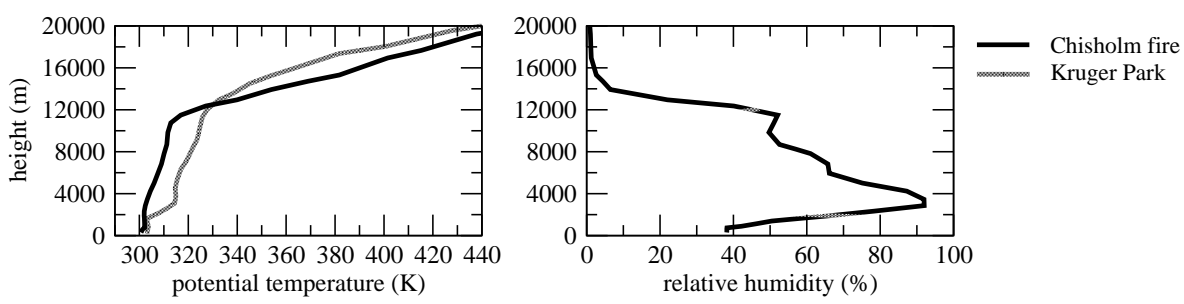

Fig. 3. Meteorological conditions given by ERA40, potential temperature in K and relative humidity in \% at two fire locations: $55 \mathrm{~N} / 114 \mathrm{~W}$ the 28 May 2001 at 16:30 LT for the Chisholm fire and 25 S/31 E the 24 September 1992 at 14:00 LT for the Kruger fire.
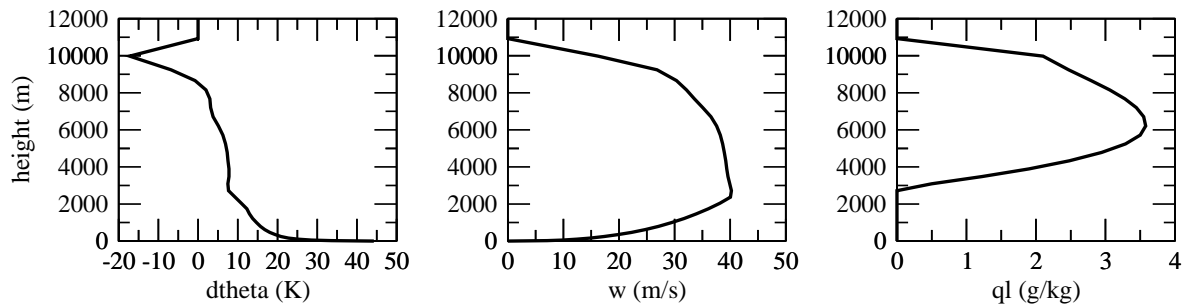

Fig. 4. Plume characteristics above the Chisholm fire: virtual potential temperature excess $(\mathrm{K})$, vertical velocity ( $\mathrm{m} \mathrm{s}^{-1}$ ) and cloud liquid water $\left(\mathrm{g} \mathrm{kg}^{-1}\right)$.

The plume generated by the Chisholm fire has been simulated with the 3-D mesoscale ATHAM model (Active Tracer High resolution Atmospheric Model, Oberhuber et al., 1998; Herzog et al., 1998) by Trentmann et al. (2006) and Luderer et al. (2006). The horizontal resolution used is of $100 \mathrm{~m}$ while the vertical resolution varies from $50 \mathrm{~m}$ near surface to $150 \mathrm{~m}$ at the tropopause. The pyro-plume is thus explicitly resolved and we use results from their simulations as a reference. From their studies we extract fire characteristics we need to initialize the pyro-thermal plume model. The quantity of consumed fuel is estimated to be $\omega=76000 \mathrm{~kg} \mathrm{ha}^{-1}$. The speed rate at which the fire propagates is $v=1.5 \mathrm{~m} \mathrm{~s}^{-1}$. Trentmann et al. (2006) consider a fire front $15 \mathrm{~km}$ large and $300 \mathrm{~m}$ deep. From this depth $d$ of the fire front we can deduce the heat flux released by the fire $F=I / d$. Thus, for the Chisholm fire, we obtain $I=202703 \mathrm{~kW} \mathrm{~m}^{-1}$ and $F=675 \mathrm{~kW} \mathrm{~m}^{-2}$. As suggested by Luderer et al. (2006), 50\% of this heat flux is assumed to be effectively used for convection, the other half for radiation. However this distribution is still subject to discussions.

Characteristics of the plume simulated by the pyro-thermal plume model for a heat flux $F=337.5 \mathrm{~kW} \mathrm{~m}^{-2}$ and an active burning area $S=4.5 \mathrm{~km}^{2}$ are represented in Fig. 4. Main features are compared in Table 1 with values extracted from Trentmann et al. (2006) (values are approximately deduced from their Figs. 10 and 11). An excess of temperature of an order of $40 \mathrm{~K}$, as well as a maximal vertical velocity of $40 \mathrm{~m} \mathrm{~s}^{-1}$ are obtained. Those features are in reasonable agreement with Trentmann et al. (2006) results, even if the
Table 1. Comparison of plume characteristics (injection height, virtual potential temperature excess, maximum vertical velocity) as obtained with the ATHAM high resolution model in Trentmann et al. (2006) and with the pyro-thermal plume model.

\begin{tabular}{ccc}
\hline & Trentmann et al. (2006) & pyro-thermal \\
\hline $\mathrm{Z}_{\max }$ & $12000 \mathrm{~m}$ & $10200 \mathrm{~m}$ \\
$\theta_{0}^{\prime}$ & $40 \mathrm{~K}$ & $44 \mathrm{~K}$ \\
$\mathrm{~W}_{\max }$ & $40 \mathrm{~m} \mathrm{~s}^{-1}$ & $40 \mathrm{~m} \mathrm{~s}^{-1}$ \\
\hline
\end{tabular}

evaluation of the scheme stays rough at this stage. However, the simulated injection height of $10200 \mathrm{~m}$, is slightly too low and does not allow emissions to reach the stratosphere located at $12 \mathrm{~km}$.

\subsection{Fire in the Kruger National Park in South Africa}

We now consider a savanna fire that took place in the Kruger National Park in South Africa during the SAFARI campaign in 1992. Environmental conditions from ERA40 reanalysis at fire location $(25 \mathrm{~S} / 31 \mathrm{E})$ the 24 September 1992 at 14:00 LT are shown in Fig. 3. The inversion at the top of the boundary layer is much stronger than for the Chisholm fire. The mixed layer is estimated to be around $1500 \mathrm{~m}$.

Results are more difficult to evaluate because vertical characteristics of the convective plume are not referenced. However, Stocks et al. (1996) report a plume reaching about $2717 \mathrm{~m}$ just before 14:00 LT with a small cumulus at the top. 

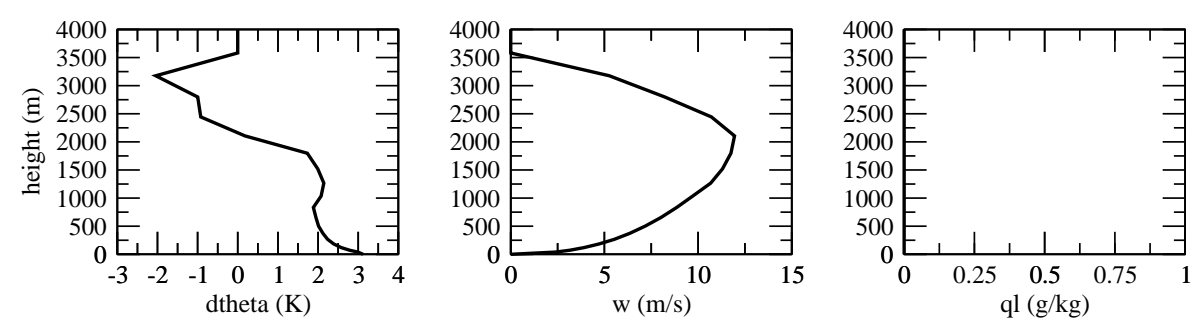

Fig. 5. Plume characteristics above the Kruger fire: virtual potential temperature excess (K), vertical velocity ( $\mathrm{m} \mathrm{s}^{-1}$ ) and cloud liquid water $\left(\mathrm{g} \mathrm{kg}^{-1}\right)$.

They estimate the density of savanna burned to $3786 \mathrm{~kg} \mathrm{ha}^{-1}$. The fire lasted several hours, devastating 2333 ha. The propagating rate is estimated to be $1.62 \mathrm{~m} \mathrm{~s}^{-1}$ (Stocks et al., 1996). From those characteristics, we can deduce the intensity of the fire front $I=10906 \mathrm{~kW} \mathrm{~m}^{-1}$ for $d \approx 700 \mathrm{~m}$ and a heat flux $F=15.6 \mathrm{~kW} \mathrm{~m}^{-2}$ (50\% of which is assumed to be available for convection). As can be noted, those values are far weaker than those related to the boreal forest fire in Canada. Plume characteristics obtained with those definitions and an estimated active burning surface of $1 \mathrm{~km}^{2}$ are represented in Fig. 5.

The excess of virtual potential temperature is of $3.1 \mathrm{~K}$ in the first model layer, more than ten times weaker than for the Chisholm fire. This excess is of $2 \mathrm{~K}$ at $1000 \mathrm{~m}$ and becomes negative above $2000 \mathrm{~m}$, where the vertical velocity is maxi$\mathrm{mal}$ and of $12 \mathrm{~m} \mathrm{~s}^{-1}$. No pyro-cloud form above the fire and the thermal plume reaches $3300 \mathrm{~m}$. Comparing with observations from Stocks et al. (1996), the plume height is $600 \mathrm{~m}$ too high, with no cumulus cloud at the top.

\subsection{How to explain discrepancies?}

These tests of the pyro-thermal plume model on two different cases, a pyro-plume reaching the stratosphere in boreal regions and a plume being trapped in the lower troposphere in South Africa, bring into evidence some differences between results and observations which can have several sources. First, the plume initiation is controlled by fire characteristics, the heat flux available for convection and the active burning area, on which large uncertainties still remain. Second, the thermal plume model has been initially developed to represent shallow plumes induced by an excess of temperature of the order of $1 \mathrm{~K}$. It is thus used here in configurations for which the scheme has not been initially developed for, possibly leading to deep convection. As mixing intensity is different whether convection is shallow or deep, we modified the definitions initially prescribed for shallow convection by choosing a formulation depending on plume dimensions, potentially adapted to both shallow and deep convection. However, this intermediate formulation may explain the underestimation of the plume height generated by the Chisholm fire and the overestimation of the plume height generated by the Kruger fire. We also neglected the water release in the plume by biomass burning. Sensitivity tests on all these parameters are performed in the next section.

\subsection{Sensitivity to fire characteristics and scheme parameters}

\subsubsection{Sensitivity to fire characteristics}

Injection heights obtained by varying either the heat flux released or the active burning area are represented in Fig. 6 for the two environmental conditions of the Chisholm fire and the Kruger fire. In the boreal conditions of the Chisholm fire, there is a sharp transition from plumes confined in the mixed layer to plumes reaching $10 \mathrm{~km}$ when the heat flux released increases from $5 \mathrm{~kW} \mathrm{~m}^{-2}$ to $20 \mathrm{~kW} \mathrm{~m}^{-2}$ for an active burning surface of $4.5 \mathrm{~km}^{2}$, or when the active burning area increases from $0.4 \mathrm{~km}^{2}$ to $1 \mathrm{~km}^{2}$ for a heat flux released of $337.5 \mathrm{~kW} \mathrm{~m}^{-2}$. In the conditions encountered in the Kruger National Park, the evolution of the injection height depending on the heat flux released is more continuous. However, if the heat flux could reach values encountered in boreal regions, the injection height would reach $7000 \mathrm{~m}$ in such conditions. Such injection height can also result from very large fire fronts $\left(10 \mathrm{~km}^{2}\right)$ for realistic heat flux in that region.

The injection height is thus sensitive to both environmental conditions and fire characteristics, as already reported by Kahn et al. (2007); Trentmann et al. (2002); Freitas et al. (2007). However, in a reasonable range of estimated values of the heat flux and of the active burning area in the cases of the Chisholm fire and the Kruger fire, the simulated injection height does not vary significantly.

In the standard version of the pyro-thermal plume model, the water available for condensation is that provided by lateral entrainment of surrounding air. A test was also performed in which the additional water coming from the burned biomass is taken into account, assuming that each kilogramm of biomass burned releases half a kilogramm of water, so that the corresponding excess of water at the base of the plume is:

$q_{0}^{\prime}=\frac{F_{q}}{\rho w_{0}}$

with $F_{q}=0.5 \mathrm{~kg} \mathrm{~kg}^{-1}$. 

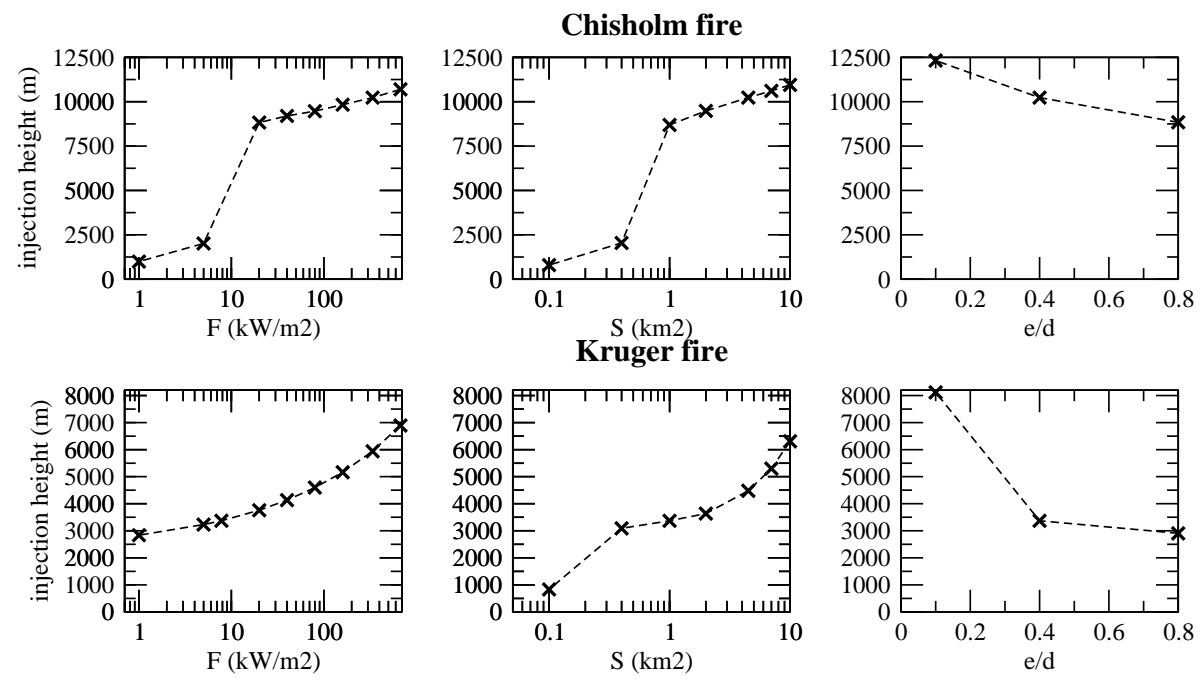

Fig. 6. Sensitivity of the injection height to the heat flux released $(F)$, the active burning surface $(S)$, and the ratio e/d for the Chisholm fire (top) and Kruger fire (bottom) conditions.

For the Chisholm fire, the injection height increases from 10230 to $10370 \mathrm{~m}$ and for the Kruger fire from 3370 to $3400 \mathrm{~m}$. As already mentionned by Luderer et al. (2006), taking into account the water released by the biomass burned seems to have no significant impact on the injection height.

\subsubsection{Sensitivity to scheme parameters}

As already mentionned, mixing with environmental air plays a major role in convection dynamics. Entrainment in particular drives the plume characteristics. The sensitivity of the injection height to $\beta=e / d$ is given in Fig. 6 (right). For the Chisholm fire, $e / d=0.1$ allows to simulate a plume reaching $12 \mathrm{~km}$, while for the Kruger fire, $e / d=0.8$ leads to an injection height lower than $3 \mathrm{~km}$, in better agreement with observations. Thus, $e / d=0.1$ seems to be better suited for deep plumes while $e / d=0.8$ for shallow plumes. This point deserves further investigations, however $e / d=0.4$ is an intermediate value which allows to obtain satisfactory results for the two very different cases considered here.

The sensitivity of the injection height to the parameter $\lambda$ controlling the detrainment in the mixed layer is weak (not shown). Here we keep $\lambda=30 \mathrm{~m}$ as in the original thermal plume model.

Even if there are some discrepancies between model results and observations or high resolution simulations available for the Chisholm fire and the SAFARI fire in the Kruger National Park, the pyro-thermal plume model proposed here is able to reproduce the main features of the pyro-plumes in those two cases and is thus appropriate to simulate injection heights for a large range of conditions. In the next section, the scheme is used to evaluate injection heights and $\mathrm{CO}_{2}$ transport at regional scale over Southern Africa.

\section{Application to pyro-plumes in Southern Africa and to their impact on the diurnal cycle of $\mathrm{CO}_{2}$ in the free troposphere}

\subsection{The diurnal cycle of fire characteristics}

Several studies report that the normalized frequency of fires follows a strong diurnal cycle, active fire pixels being maximum in mid-afternoon (Giglio, 2007; Justice et al., 2002). Here we assume that this diurnal cycle is close to a Gaussian centered around 15:45 LT with a standard deviation of $1 \mathrm{~h}$. This Gaussian function is used to specify the diurnal evolution of fire heat flux and related $\mathrm{CO}_{2}$ emissions. The instantaneous heat flux $F$ and flux of $\mathrm{CO}_{2}$ released by fires $F_{\mathrm{CO}_{2}}$ are thus specified by:

$F(t)=\bar{F} N(t)$

and

$F_{\mathrm{CO}_{2}}(t)=\overline{F_{\mathrm{CO}_{2}}} N(t)$

where $\bar{X}=\frac{1}{T} \int_{0}^{T} X(t) d t, T$ being the duration of one day and $N$ the normalized Gaussian centered around 15:45 LT and of standard deviation $\sigma=1 \mathrm{~h}(\bar{N}=1)$.

Typical values for $\bar{F}$ and $\overline{F_{\mathrm{CO}_{2}}}$ encountered in Southern Africa need to be specified. However, the pyro-thermal plume model is not able to take into account the variability of fire characteristics within a grid cell. As an alternative, we choose to specify mean values of fire characteristics which may contribute the most to the total emissions. Korontzi et al. (2003) estimate that in semi-arid regions, $60 \%$ of the total area burned is related to $3 \%$ of the fires, those burning more than $100 \mathrm{~km}^{2}$, while $43 \%$ of fires burn less than 


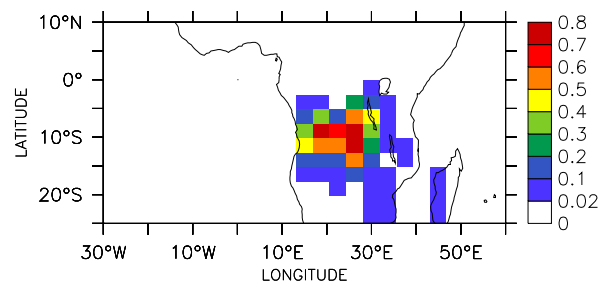

Fig. 7. Mean $\mathrm{CO}_{2}$ emissions from biomass burning in $\mathrm{kg} \mathrm{m}^{-2}$ day $^{-1}$ for July 2006 over Southern Africa as derived by (Liousse et al., 2010) and extrapolated to the GCM grid.

$1 \mathrm{~km}^{2}$, devastating only $2 \%$ of the total area burned in those regions. The larger fires are thus the less frequent, but are responsible for most of the emissions, and for the most intense pyro-plumes. This is why we choose to consider such large fires in the following. During the dry season 1989, Barbosa et al. (1999) report a total burned area over the season of $1541000 \mathrm{~km}^{2}$ for $456 \mathrm{Tg}$ of biomass burned. This corresponds to a density of biomass burned of $2960 \mathrm{~kg} \mathrm{ha}^{-1}$. If we consider a propagation rate of $1.5 \mathrm{~m} \mathrm{~s}^{-1}$, the fire front intensity is $I=7894 \mathrm{~kW} \mathrm{~m}^{-1}$, which corresponds to a heat flux $F=99 \mathrm{~kW} \mathrm{~m}^{-2}$ for a front depth $d=80 \mathrm{~m}$ or $F=39 \mathrm{~kW} \mathrm{~m}^{-2}$ for $d=500 \mathrm{~m}$. Values for $F$ of dozens of $\mathrm{kW} \mathrm{m}^{-2}$ seem reasonable, an intermediate value between the Chisholm fire and the Kruger fire. For simplicity, the active burning area of a fire is kept constant during the day, and we take $S=2 \mathrm{~km}^{2}$. This value is quite large, but does not intend to take into account the restrictive active burning area, but an area warmed enough by the fire to initiate convection, which may include the flaming part of the fire and the just burnt surrounding area. The integration of Eq. (1) in time gives:

$S \int_{0}^{T} F(t) d t=\Sigma_{\mathrm{tot}} E$

so that we have:

$\bar{F}=\frac{\Sigma_{\mathrm{tot}} E}{S T}$

We consider a maximum value for $F$ of $80 \mathrm{~kW} \mathrm{~m}^{-2}$. For $\overline{F_{\mathrm{CO}_{2}}}$, we use monthly mean emissions for July 2006 as derived by Liousse et al. (2010) in the framework of the AMMA field campaign at a daily scale with a resolution of $1 \mathrm{~km} \times 1 \mathrm{~km}$. Emissions estimates are computed from burnt areas given by the L3JRC product using Spot-Vegetation satellite (Tansey et al., 2008), the Global Land Cover vegetation map developed at JRC-Ispra, biomass densities and burning efficiencies from AMMA observations (Mieville et al., 2009). Figure 7 displays the mean emissions over July extrapolated to the GCM grid.

\subsection{Set up of 3-D simulations}

Simulations are performed with the standard version of LMDZ (Hourdin et al., 2006) with an horizontal grid made of 72 points equally distributed from pole to pole and 96 points in longitude $(2.5 \times 3.75$ degrees), a vertical resolution of 40 layers over the entire atmospheric column and a time step of $90 \mathrm{~s}$ for a typical month of July. The model includes parameterizations of boundary layer turbulence (Louis, 1979), deep convection (Emanuel, 1991), clouds (Bony and Emanuel, 2001) and radiation (Morcrette, 1984). Two types of simulations are conducted: a reference simulation with the standard version of LMDZ in which $\mathrm{CO}_{2}$ emissions are injected uniformly in the first model layer (REF), and a simulation in which the pyro-thermal plume model is activated (TH) and emissions are injected at the base of the pyro-thermal. In that case, the flux of $\mathrm{CO}_{2}$ at level $\mathrm{H}$ must equal the surface flux of $\mathrm{CO}_{2}$. The concentration of $\mathrm{CO}_{2}$ at the base of the plume is thus:

$q_{\mathrm{CO}_{2}}(t)=\frac{F_{\mathrm{CO}_{2}}(t)}{\alpha \rho w_{0}(t)}$

\subsection{Injection heights}

The simulated injection height varies in space and time as it depends on the heat flux and environmental conditions. The maximal injection height computed over the 20 last days of July with simulation TH is represented in Fig. 8 (left). The maximal simulated injection height varies from $2500 \mathrm{~m}$ in the East to $6000 \mathrm{~m}$ in the center of the continent and reaches $7500 \mathrm{~m}$ in the south-west of the considered region.

This maximal injection height is compared with the mean injection height reached when emissions pass the boundary layer height and with the mean boundary layer height in Fig. 8 (middle), where heights are averaged between $5 \mathrm{~S}$ and $20 \mathrm{~S}$. The boundary layer height is located around $2 \mathrm{~km}$. When emissions are directly injected above the boundary layer, they reach in average $4 \mathrm{~km}$ and can sometimes be lifted higher up to $7 \mathrm{~km}$. The percentage of cases for which, the injection height passing $2 \mathrm{~km}$, it is finally larger than $4 \mathrm{~km}$ is represented in Fig. 8 (right). Those results show that part of fire emissions from intense fires in the Tropics can be directly injected above the boundary layer in the free troposphere, and if so, in more than $30 \%$ of cases directly between 4 and $7 \mathrm{~km}$ over the South-West part of Southern Africa.

\section{4 $\mathrm{CO}_{2}$ transport at global scale}

The vertical distribution of $\mathrm{CO}_{2}$ averaged over the 20 last days of July between $5 \mathrm{~S}$ and $20 \mathrm{~S}$ is represented in Fig. 9 for simulations REF (left) and TH (middle). In both simulations, $\mathrm{CO}_{2}$ is emitted in the first model layer, uniformely in simulation REF, only in the grid area covered by the pyro-plume in simulation TH. It is then transported by the different parameterizations of LMDZ (boundary layer turbulence, deep convection and pyro-convection for $\mathrm{TH}$ ). The activation of the 

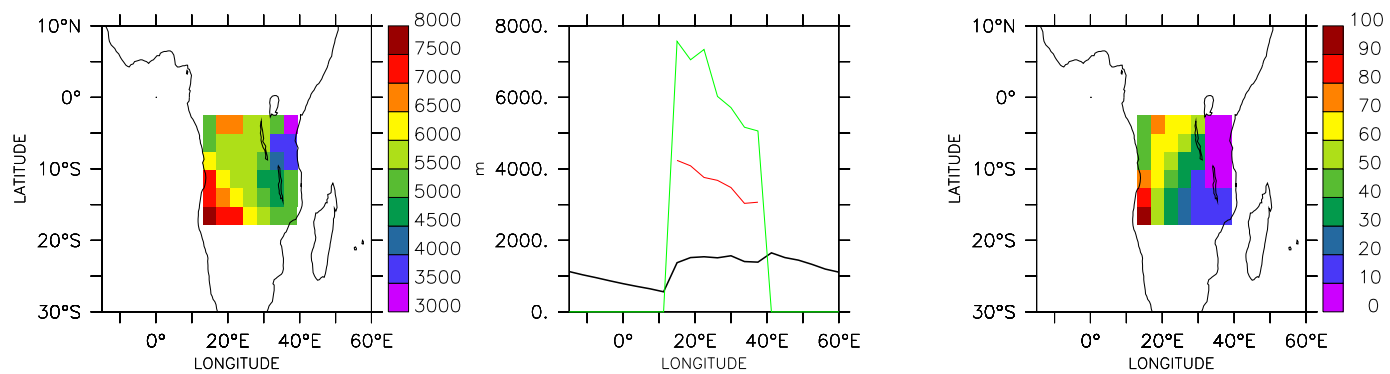

Fig. 8. Injection height of $\mathrm{CO}_{2}$ emissions: Maximal injection height (m) simulated between the 10 and the 30 July (left); maximal injection height (green), mean injection height of emissions injected above the boundary layer height (red), and mean boundary layer height (dark) averaged between 5 and $20 \mathrm{~S}$ over 20 days of simulation in July (middle); percentage of cases for which, the injection height passing the boundary layer height, it is finally higher than $4 \mathrm{~km}$ (right).
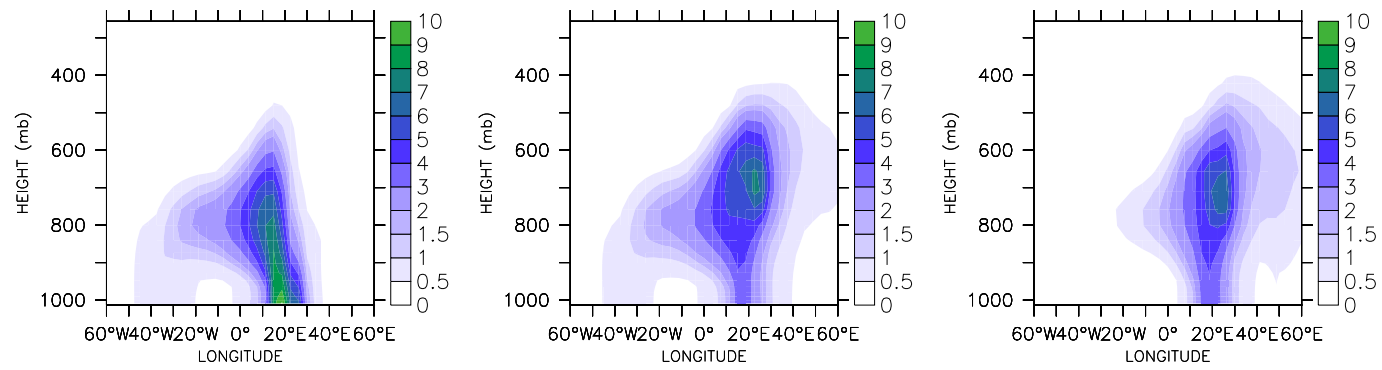

Fig. 9. Vertical distribution of $\mathrm{CO}_{2}$ mixing ratio in ppmv averaged between 5 and $20 \mathrm{~S}$ over the 20 last days of July for simulations REF (left), TH (middle) and TH with $\beta=0.1$ (right).

pyro-thermal plume model mainly affects the vertical distribution of $\mathrm{CO}_{2}$ over Southern Africa. In simulation REF, the concentration is maximal near surface and decreases above boundary layer top. When the pyro-thermal plume model is activated, the maximal concentration is located around $700 \mathrm{hPa}$ so that the concentration within the boundary layer is less and emissions are spread farther to the east at higher levels. The peak of the $\mathrm{CO}_{2}$ concentration vertical distribution is also shown for those simulations in Fig. 10 for the region from $60 \mathrm{~W}$ to $60 \mathrm{E}$ and $30 \mathrm{~S}$ to $10 \mathrm{~N}$. This figure confirms that $\mathrm{CO}_{2}$ is transported farther to the north in the REF simulation and farther to the east in the $\mathrm{TH}$ simulation.

As illustrated in the right panels of Figs. 9 and 10, where results are displayed for a simulation in which $\beta=e / d=0.1$, the $\mathrm{CO}_{2}$ vertical and horizontal distribution may also depend on the specification of mixing between the plume and the environment which determines the heights where $\mathrm{CO}_{2}$ from the plume is detrained into the troposphere. This modifies the mass-flux and then both entrainment and detrainment at each level. With $\beta=0.1$, less $\mathrm{CO}_{2}$ is detrained at low levels, where easterlies are dominant, which explains the difference of the $\mathrm{CO}_{2}$ distribution over the Atlantic Ocean. More $\mathrm{CO}_{2}$ is detrained at higher levels, between 600 and $500 \mathrm{hPa}$, where it is transported down eastward. Those results illustrate how the scheme could be further evaluated, for example to specify the value of $\beta$, from observations of $\mathrm{CO}_{2}$ concentration in that region.

\subsection{Diurnal cycle of $\mathrm{CO}_{2}$ in the troposphere}

The pyro-thermal plume model is now used to investigate the potential impact of pyro-plumes on the diurnal cycle of $\mathrm{CO}_{2}$ in the free troposphere. A vertical section of the amplitude of the simulated diurnal cycle of $\mathrm{CO}_{2}$ (difference between 19:30 LT and 07:30 LT) averaged between 5 and $20 \mathrm{~S}$ and over the 20 last days of July is represented in Fig. 11 for simulations REF (left) and TH (right). In the reference simulation, the $\mathrm{CO}_{2}$ evening excess is maximal near the surface in a range between 4 and 8 ppmv. Above, the signal decreases and vanishes around $800 \mathrm{hPa}$. When the pyro-thermal plume model is activated, the signal has two maximal values, one near the surface of about $1 \mathrm{ppmv}$ and another one around $700 \mathrm{hPa}$, reaching $3 \mathrm{ppmv}$. This maximum is related to $\mathrm{CO}_{2}$ being rapidly transported from the surface and detrained from pyro-clouds.

Those results can be explained by the following "back of the enveloppe" estimation of the atmospheric $\mathrm{CO}_{2}$ concentration increase due to fires and the corresponding diurnal 

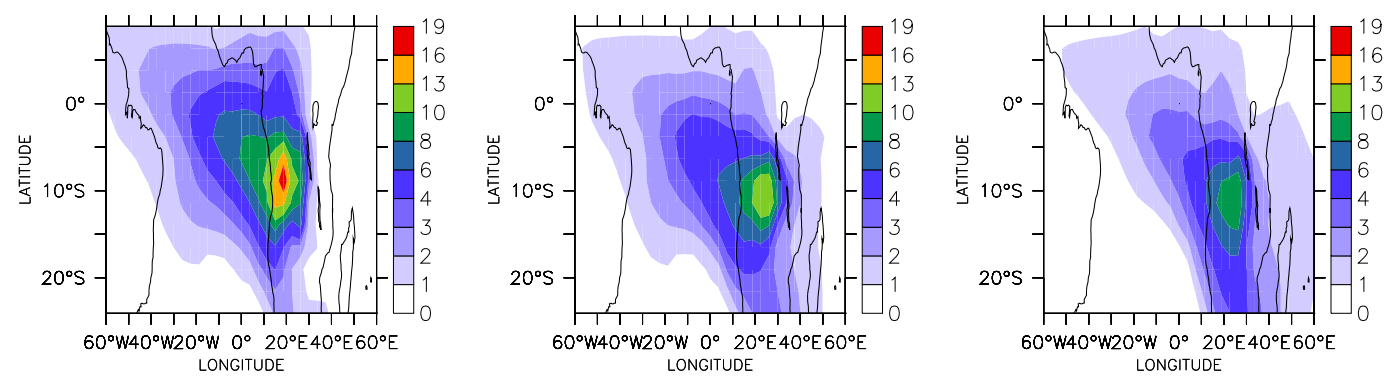

Fig. 10. Peak of the $\mathrm{CO}_{2}$ mixing ratio vertical distribution averaged over the 20 last days of July for simulations REF (left), TH (middle) and TH with $\beta=0.1$ (right).
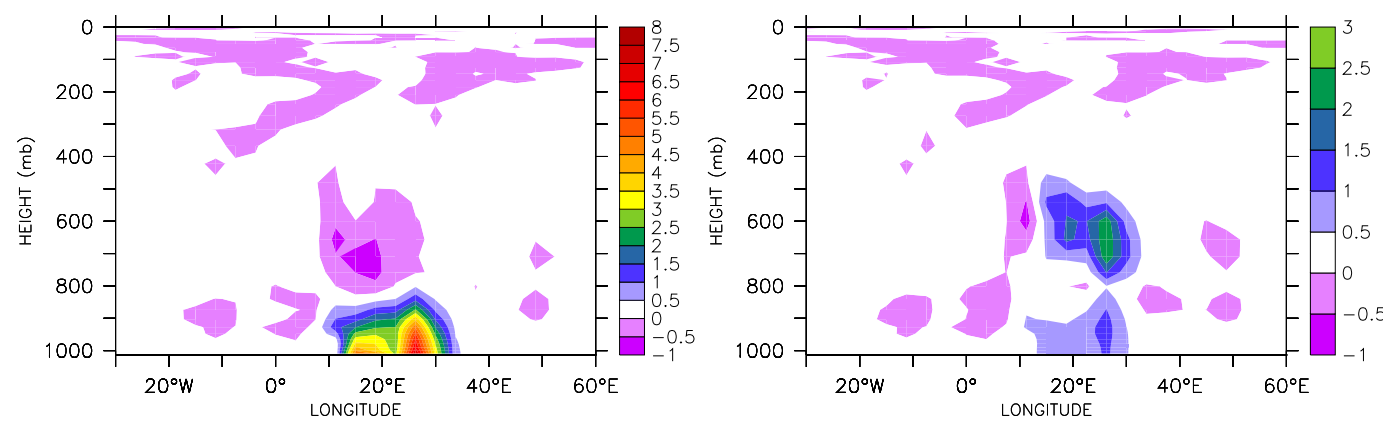

Fig. 11. Vertical section of the amplitude of the diurnal cycle of $\mathrm{CO}_{2}$ (ppmv) averaged between $5 \mathrm{~S}$ and $20 \mathrm{~S}$ over the 20 last days of July for simulation REF (left) and TH (right).

cycle. The fire induced convection introduces a vertical distribution function $(I)$ for the effective injection of $\mathrm{CO}_{2}$, so that the increase of $\mathrm{CO}_{2}$ over one day due to fire emissions alone at pressure level $p$ reads:

$\epsilon(p)=\lambda F_{\mathrm{CO}_{2}} \delta t I(p)$

where $\lambda$ is the factor converting the flux of $\mathrm{CO}_{2}$ into a concentration of $\mathrm{CO}_{2}$ (in ppmv):

$\lambda=\frac{g}{P_{s}} \frac{\mu_{\text {air }}}{\mu_{\mathrm{CO}_{2}}}$

$P_{S}$ being the surface pressure and

$\frac{1}{P_{S}} \int I(p) d p=1$

Starting from a $\mathrm{CO}_{2}$ free atmosphere, the $\mathrm{CO}_{2}$ concentration in the region of fires will build up days long under fire emissions, until an averaged balance is reached between daily $\mathrm{CO}_{2}$ injection $\epsilon$ and daily ventilation by large-scale advection. This latter term is of the order of $-\frac{V \delta t}{L} \mathrm{CO}_{2}^{\mathrm{eq}}, V$ being a typical wind speed, $L$ the size of the source region and $\mathrm{CO}_{2}^{\text {eq }}$ the $\mathrm{CO}_{2}$ concentration at equilibrium, so that:

$\mathrm{CO}_{2}^{\mathrm{eq}}=\frac{\epsilon L}{V \delta t}$
Half of the ventilation occurs during the night, so that the evening minus morning difference of $\mathrm{CO}_{2}$ concentration equals $\frac{V \delta t}{2 L} \mathrm{CO}_{2}^{\mathrm{eq}}=\epsilon / 2$. As a first approximation, we can expect the evening minus morning difference of $\mathrm{CO}_{2}$ concentration to be half the concentration increase per day due to biomass burning emissions that would occur without considering any ventilation. Note that this means that this evening excess of $\mathrm{CO}_{2}$ does not depend on the large-scale circulation, but only on the increase of $\mathrm{CO}_{2}$ concentration per day. This relationship between the evening minus morning difference of $\mathrm{CO}_{2}$ concentration and the daily $\mathrm{CO}_{2}$ injection, as well as the role of the large-scale circulation, are illustrated more explicitly on a 1-D and a 2-D ideal cases in the Appendix A.

As a first estimation, let us consider a source of $1000 \mathrm{~g} \mathrm{~m}^{-2}$ month $^{-1}\left(\approx 30 \mathrm{~g} \mathrm{~m}^{-2} \mathrm{day}^{-1}\right)$ which injects $\mathrm{CO}_{2}$ between 07:30 LT and 19:30 LT in a layer $300 \mathrm{hPa}$ deep. In that layer, we get an increase of $\mathrm{CO}_{2}$ in one day of $\epsilon=6.5 \mathrm{ppmv}$. The evening minus morning difference of $\mathrm{CO}_{2}$ in that layer will then be of an order of $\epsilon / 2=3.25 \mathrm{ppmv}$. This value is close to the maximum obtained around $700 \mathrm{hPa}$ with simulation TH (Fig. 11). 


\subsection{Simulation of the satellite retrieved Daily Tropospheric Excess}

The previous estimation considers the effective amount of $\mathrm{CO}_{2}$ released to the atmosphere. However, observations of the DTE are sensitive to only a part of the atmosphere as illustrated by the weighting function in Fig. 12 (after Chédin et al., 2003). The observed DTE is thus the vertically integrated evening minus morning difference obtained with the weighting function $(W)$, so that:

$\mathrm{DTE}=\frac{1}{P_{s}} \int_{p s}^{0}\left(\mathrm{CO}_{27 p m}-\mathrm{CO}_{27 a m}\right) W(p) d p$

Observations of the DTE signal in July is represented in Fig. 13 (after Chédin et al., 2008). It reaches 3 ppmv over Southern Africa. The simulated DTE obtained with simulations REF and TH are displayed in Fig. 14. In simulation $\mathrm{REF}$, a $\mathrm{CO}_{2}$ excess of a few $0.1 \mathrm{ppmv}$ is obtained around $5 \mathrm{~N}$ and around $10 \mathrm{~S}$, while a deficit of $\mathrm{CO}_{2}$ is obtained around $5 \mathrm{~S}$, both over land and ocean. The signal obtained in the Northern Hemisphere in simulation REF may be related to the diurnal cycle of deep convection which is very active in the Northern Hemisphere in that season. As already seen in Fig. 10, emissions are transported farther to the north in simulation REF, where they can be transported to still upper levels by deep convection. In simulation TH, results are much closer to observations. As observed, the largest signal is obtained over the region where $\mathrm{CO}_{2}$ was emitted. The restriction of the signal over a specific region is due to the averaging over several days. Indeed, a DTE signal is also obtained daily in each simulation over other regions, particularly over ocean. But due to different advection scales, the DTE signal is not at the same location from day to day so that the averaged results give a DTE signal only significant over the region where it is most persistent. The analysis of the simulated daily DTE versus observations is further shown in Chédin et al. (2009). Those results confirm that the DTE signal can be attributed to the diurnal cycle of fire activity, with $\mathrm{CO}_{2}$ being transported from the surface to levels above the boundary layer height along the day.

The DTE signal can also be directly estimated from biomass burning $\mathrm{CO}_{2}$ emissions using the previous derivation for which $\mathrm{CO}_{2}$ is uniformly emitted between 800 and $500 \mathrm{hPa}$ :

$\mathrm{DTE}=\frac{1}{P_{s}} \int_{p} \frac{\epsilon}{2} W(p) d p=F_{\mathrm{CO}_{2}} \delta t \frac{g}{2 P_{s}} \frac{\mu_{\mathrm{air}}}{\mu_{\mathrm{CO}_{2}}} \Gamma$

where $\Gamma$ is a factor defined from the vertical distribution function of fire emissions and the weighting function:

$\Gamma=\frac{1}{P_{s}} \int I(p) W(p) d p$

If we consider that $I(p)=1$ between 500 and $800 \mathrm{hPa}$ and 0 elsewhere, we get $\Gamma_{650}=0.31$ and the DTE signal obtained

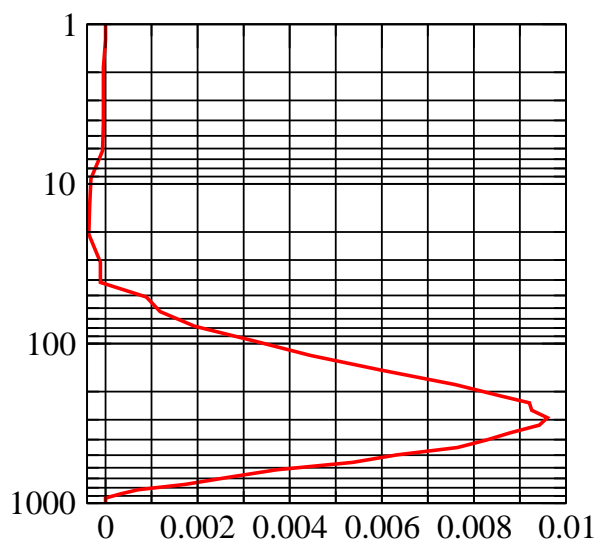

Fig. 12. Weighting function of $\mathrm{CO}_{2}$ column satellite as determined by Chédin et al. (2003).

from $\mathrm{CO}_{2}$ emissions is displayed in Fig. 14 (right). The spatial distribution of the DTE obtained is quite close to the simulated one with simulation TH. By construction however, this direct scaling of surface emissions is zero outside of the source region, while the real DTE signal can be significant in surrounding areas, due to preferential directions of the largescale advections.

The DTE signal is between 0.5 and 1 ppmv over the source region. This value is still lower than the 3 ppmv observed by Chédin et al. $(2005,2008)$. This difference can be due to several uncertainties in both observations and modelling. Equation (30) allows to distinguish three different sources of uncertainties: estimation of $\mathrm{CO}_{2}$ emissions from biomass burning $\left(F_{\mathrm{CO}_{2}}\right)$, determination of the vertical distribution of those emissions in the atmosphere (the function I simulated, for example, by the pyro-thermal plume model), and the derivation of the weighting function of satellite observations. Large uncertainties are still related to $\mathrm{CO}_{2}$ emissions from biomass burning, which are deduced from several variables independently evaluated, among them the burning area. In addition, the simulation performed here corresponds to July 2006 while the observed signal is averaged between 1987 and 1990. The difference could thus be due to interannual variability of $\mathrm{CO}_{2}$ emissions. Concerning the pyrothermal plume model, the simulated vertical distribution of $\mathrm{CO}_{2}$ emissions strongly depends on the prescribed mixing rates between the plume and its environment. This point has to be investigated further in the future using observations and high resolution simulations of pyro-plumes. Uncertainties of an order of $50 \mathrm{hPa}$ may also affect the location of the peak of the weighting function of satellite observations. Of course the maximum DTE signal would be obtained in case the peaks of the distributions $I$ and $W$ coincide. By shifting the peak of the vertical distribution of $\mathrm{CO}_{2}$ concentration $I$ from 650 to $350 \mathrm{hPa}$, we get: $\Gamma_{550}=0.47, \Gamma_{450}=0.57$ and $\Gamma_{350}=0.64$ leading to a factor 2 on the DTE signal obtained. 


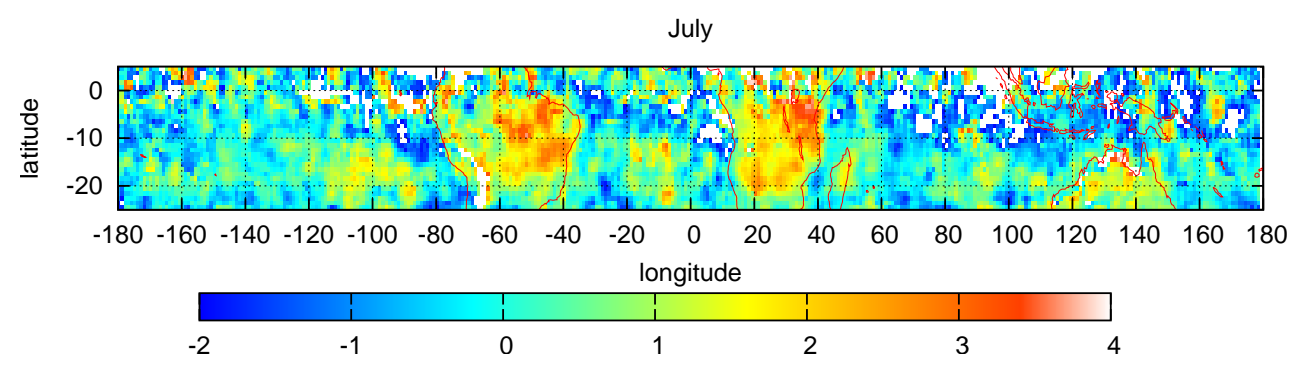

Fig. 13. Daily Tropospheric Excess (ppmv) in July retrieved from satellite measurements by Chédin et al. (2003).
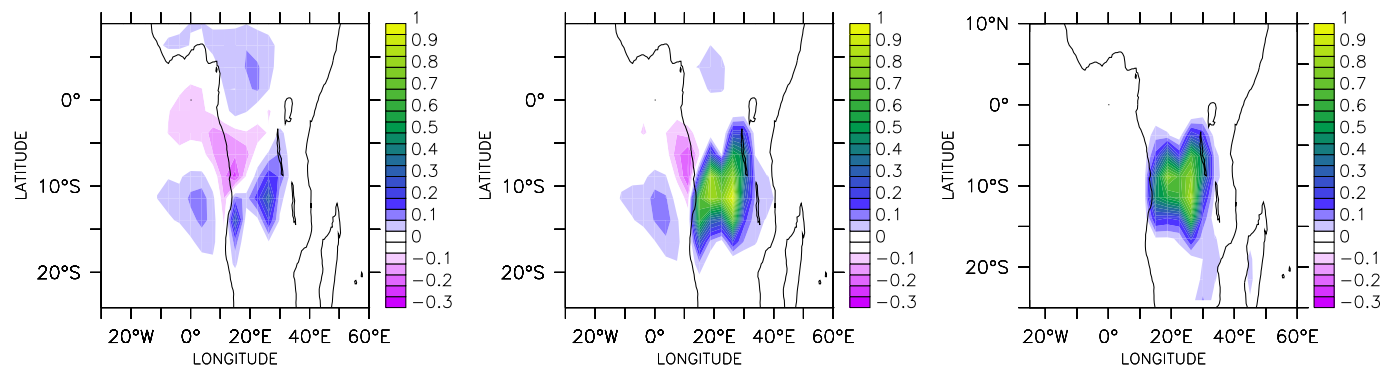

Fig. 14. Daily Tropospheric Excess of $\mathrm{CO}_{2}$ (ppmv) in July as simulated by simulations REF (left) and TH (middle) and estimated from $\mathrm{CO}_{2}$ emissions by assuming a uniform injection of $\mathrm{CO}_{2}$ emissions between 800 and $500 \mathrm{hPa}$ (right).

Note that part of the differences between the simulated and observed DTE could also come from contaminations of the retrieved DTE signal by either ozone, dust or smoke aerosols, or remaining (undetected) thin clouds, however not expected to exceed $1 \mathrm{ppm}$ at that time of the year (see Chédin et al., 2009).

\section{Conclusions}

In the present study, the thermal plume model of Rio and Hourdin (2008) is adapted to the representation of the vertical transport by plumes generated by fires. The model computes the vertical distribution of fire emissions induced by pyro-convection given fire characteristics (burning area and heat flux released) and environmental conditions. The model is first shown to satisfactorily reproduce the characteristics of two well documented fires in boreal and tropical regions in 1D configuration. Sensitivity tests to fire characteristics show that, despite less favourable conditions, emissions from tropical fires may also penetrate well above the boundary layer depending on the heat flux or burning area. Sensitivity tests to scheme parameters highlight the key role of mixing prescription between the pyro-plume and its environment. In the future, 3-D explicit simulations of large fire plumes may help validate, tune and improve the pyro-thermal plume model on those aspects.
When implemented in the LMDZ General circulation model, the pyro-thermal plume model injects directly a large fraction of fire products well above $4 \mathrm{~km}$, in the region of African biomass burning. Because fire emissions occur mainly during the afternoon in this region, this produces a 2-ppmv amplitude diurnal cycle of $\mathrm{CO}_{2}$ concentration in the mid-troposphere, as first suggested by Chédin et al. (2005) from remote sensing. The vertical integration of this evenings minus mornings $\mathrm{CO}_{2}$ concentration using the weighting function of satellite retrieval gives a Daily Tropospheric Excess of an order from 0.5 to $1 \mathrm{ppmv}$, which is lower than the 3 ppmv obtained by Chédin et al. (2008) from observations. The discrepancy may come from the large uncertainties that remain on fire characteristics and emissions, from the vertical distribution of $\mathrm{CO}_{2}$ above fires computed by the pyro-thermal plume model and from uncertainties on the observed DTE signal. A direct estimation of the DTE signal from $\mathrm{CO}_{2}$ emissions is also proposed, which only depends on the vertical distribution of fire emissions and on the weighting function of satellite sensitivity, and not from large-scale advection. This estimation allows recovering simply the simulated DTE signal when assuming a vertical distribution of fire emissions.

A step further would be to take fire emissions and characteristics into account more precisely. Observations of fire emissions and of the atmospheric composition from the AMMA field campaign could be used to initialize and validate the scheme at regional scale by considering other gases 

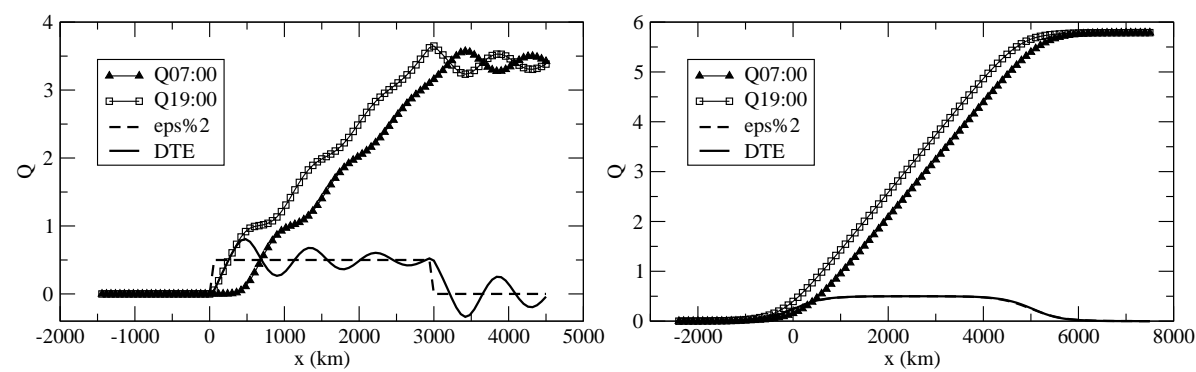

Fig. 15. DTE computation for a fire injecting emissions along $x=[0, L]$ in the presence of 1-D advection with a constant wind $U=10 \mathrm{~m} / \mathrm{s}$ for $L=3000 \mathrm{~km}(L /(U \delta t)=3)$ considering a top-hat source region (left) and $L=6000 \mathrm{~km}(L /(U \delta t)=6)$ considering smoothed emissions (right). Results are presented for day 29 with concentrations at 07:00 just before fire injection (black triangles) and at 19:00, just after fire injection (white squares). The DTE (difference between the two previous curves, dashed) is compared to half the emission $\epsilon / 2$ (dashed curve).

like $\mathrm{CO}, \mathrm{O}_{3}$. Simulations could be extended to the whole globe using global maps of $\mathrm{CO}_{2}$ emissions from biomass burning. When available, global maps of heat flux released would be very useful to compute the injection height. A promising method is the use of the Fire Radiative Power derived from satellite measurements, which integration over the lifetime of a fire should be proportional to fire emissions (Wooster et al., 2005). However, such method has not been validated at regional nor at global scale yet, even if such evaluation is in progress (Schultz et al., 2009). A scheme like the pyro-thermal plume model will be very useful to understand and predict more precisely the $\mathrm{CO}_{2}$ concentration over the globe, and help to disentangle the respective role of atmospheric transport on the one hand and of sources or sinks of $\mathrm{CO}_{2}$ on the other hand.

\section{Appendix A}

\section{Academic computations of DTE}

Here we present two idealized cases in order to illustrate the relationship between the Daily Tropospheric Excess (DTE) of $\mathrm{CO}_{2}$ and the daily injection of $\mathrm{CO}_{2}$, as well as the role played by the large-scale circulation on a daily and a monthly basis. In the first case, the fire is idealized by a segment of length $\mathrm{L}$ emitting $\mathrm{CO}_{2}$ from 07:00 LT to 19:00 LT. In the second case, the fire is a circle with a diameter of $3000 \mathrm{~km}$.

\section{A1 1-D computation}

In the first case we consider the DTE that would be created in a 1-D world by an homogeous fire area over a segment $[0, L]$, with a constant advection with wind $U$. For simplicity, we assume that fires also emit $\mathrm{CO}_{2}$ uniformely between 07:00 and 19:00 local time. We denote by $\epsilon$ the $\mathrm{CO}_{2}$ increment over 1 day due to fire emission alone (as in the main text) and by $Q$ the $\mathrm{CO}_{2}$ concentration. In this simple case, $Q=0$ upstream of the fire emission (for $x<0$ ). In the fire emission region, the average balance in quasi steady state regime is
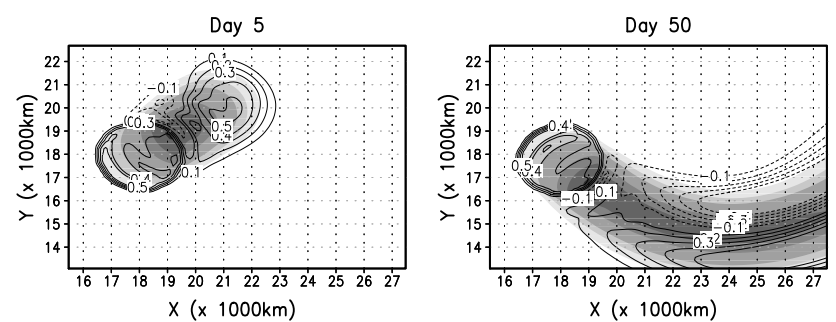

Day 60

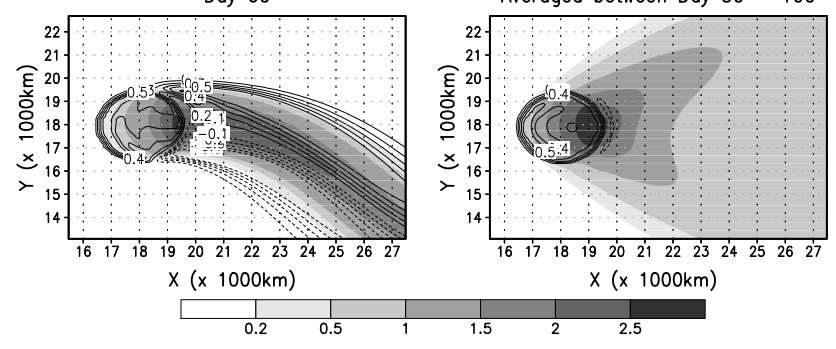

Fig. 16. DTE computation for a fire injecting emissions inside a circle of diameter $L=3000 \mathrm{~km}$ in the presence of constant advection over the domain at a given time. At time $t$, the wind in the $x$ and $y$ direction is respectively $\left.\left.U=U_{0} \sqrt{(} 1 .+\cos (2 \pi t / \tau)^{2}\right) / \sqrt{(} 2\right)$ and $V=U_{0} \sin (2 \pi t / \tau) / \sqrt{(2)}$ with $U_{0}=10 \mathrm{~m} / \mathrm{s} . \tau=1.25 \pi \delta t$ is chosen so that the oscillation of wind is not in phase with the diurnal cycle. On each panel, the concentration is shown (shaded) together with the associated DTE contours $(-0.5,-0.4,-0.3,-0.2,-0.1,0.1$, $0.2,0.3,0.4,0.5)$.

$\epsilon=-U \delta t Q_{x}$ where $\delta t=1$ day, and $Q_{x}$ is the spatial derivative of $Q$ in $x$. Since $\epsilon$ is positive and constant within the fire area, $Q$ must increase linearly from $x=0$ to $x=L$, where it reaches a value $Q_{L}=\epsilon L /(U \delta t)$.

As in our 3-D considerations, DTE $=\epsilon / 2$ since half of the $\mathrm{CO}_{2}$ sink due to advection occurs between 19:00 LT and 07:00 LT.

For $x>L$, the averaged $\mathrm{CO}_{2}$ concentration stays close to $Q_{L}$. Because the concentration is by $\epsilon / 2$ larger for $x=L$ at 19:00 LT than at 07:00 LT, exactly the opposite will be obtain beyond the emission region at $x=L+U \delta t / 2$ due to pure advection. 
This result is checked numerically for $L=3000 \mathrm{~km}$, a mesh $\delta x=100 \mathrm{~km}, U=10 \mathrm{~m} / \mathrm{s}$ and $\delta t=10^{5} \mathrm{~s}$, so that $L /(U \delta t)=3$. Advection is computed with a simple first order upstream scheme. Tracer concentration increases on the first few days to reach a steady-state diurnal cycle. Final concentrations are shown on the left panel of Fig. 15. As expected, the concentration increases linearly with $x$, to reach a value slightly larger than 3 for $x=L$. The DTE is also close to $\epsilon / 2$ on the emission region with negative values for $x \simeq L+U \delta t / 2(3500 \mathrm{~km}$ on the graph). So, compared with expectations, the maximum value is just slightly stronger and the DTE shows some oscillations. The oscillations are due to the fact that $Q_{x}$ is in steady state on a daily basis but oscillates during the day. To confirm the dependance with $L$ as well as the constancy of the DTE, we show a second computation for a wider domain of emission $(L=6000 \mathrm{~km})$. A smoothing is also applied to the emission function so that the oscillation disapears in that case (Fig. 15, right).

\section{A2 2-D computation}

The fact that $Q$ stays maximum downstream of the fire emission region is due to the 1-D domain. A similar simulation is performed with a 2-D code. The source region is a circle with a diameter of $3000 \mathrm{~km}$. The wind speed is of $U_{0}=10 \mathrm{~m} / \mathrm{s}$ but oscillates from south-westerlies to north-westerlies. For the sake of simplicity, $U_{0}$ is assumed to be constant in the whole domain.

The resulting concentration for 3 particular days is shown in Fig. 16 together with the instantaneous DTE for each day. In the same figure, the fourth panel shows the averaged concentration and DTE on the last 70 days of a 100-day simulation. At a given time, as for day 50, the DTE can be quite large outside of the source region. At this particular day, the wind is shifting from south-westerlies to westerlies. The DTE is positive north of the $Q$ horizontal plume since the $Q$ concentration increases there due to advection but it will also reinforce during the following night. Once again the quasi-steady state concentration in the fire region is of the order of $\epsilon L /(U \delta t) \simeq 3$ while the averaged DTE is of the order of $\epsilon / 2$. In addition, while the averaged concentration is still significant downstream of the emission region, the DTE is restricted to the fire region.

Results obtained here in a 1-D and a 2-D idealized cases explain results obtained in 3-D and illustrate why the DTE signal is dependent on daily emissions, and independent on large-scale circulation.

Acknowledgements. The authors kindly thank Jean-Yves Grandpeix and Philippe Ciais for fruitfull discussions without which this study could not have succeeded. They also thank Catherine Liousse for providing the $\mathrm{CO}_{2}$ emissions from biomass burning over Southern Africa used in this study.

Edited by: B. N. Duncan

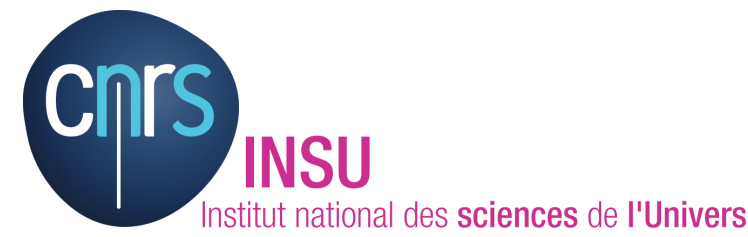

The publication of this article is financed by CNRS-INSU.

\section{References}

ASRD: Final Documentation Report - Chisholm Fire (LWF-063), Forest Protection Division, ISBN: 0-7785-1841-8, Tech. rep., Alberta Sustainable Resource Development, 2001.

Barbosa, P. M., Stroppiana, D., and Grégoire, J.-M.: An assessment of vegetation fire in Africa (1981-1991): burned areas, burned biomass, and atmospheric emissions, Global Biogeochem. Сy., 13, 933-950, 1999.

Bony, S. and Emanuel, K. A.: A parameterization of the Cloudiness Associated with Cumulus Convection; Evaluation Using TOGA COARE Data, J. Atmos. Sci., 58, 3158-3183, 2001.

Byram, G. M.: Combustion of forest fuels, in: Forest fire: Control and Use, edited by: Davis, K. P., 61-69, McGraw-Hill, NewYork, 1959.

Chédin, A., Serrar, S., Scott, N. A., Crevoisier, C., and Armante, R.: First global measurement of mid-tropospheric $\mathrm{CO}_{2}$ from NOAA polar satellites: the tropical zone, J. Geophys. Res. Atmos., 108, 4581, doi:10.1029/2003JD003439, 2003.

Chédin, A., Serrar, S., Scott, N. A., Pierangelo, C., and Ciais, P.: Impact of tropical biomass burning emissions on the diurnal cycle of upper tropospheric $\mathrm{CO}_{2}$ retrieved from NOAA 10 satellite observations, J. Geophys. Res. Atmos., 110, D11309, doi: 10.1029/2004JD005540, 2005.

Chédin, A., Scott, N. A., and Armante, R.: A quantitative link between $\mathrm{CO}_{2}$ emissions from tropical vegetation fires and the daily tropospheric excess of $\mathrm{CO}_{2}$ seen by NOAA-10 (1987-1991), J. Geophys. Res., 113, D05302, doi:10.1029/2007JD008576, 2008.

Chédin, A., Scott, N. A., Ciais, P., Rio, C., Hourdin, F., Crevoisier, C., and Armante, R.: Regional-scale correlation between $\mathrm{CO}_{2}$ fire emissions, burned areas, and mid-tropospheric $\mathrm{CO} 2$ daily variations over southern Africa, Atmos. Chem. Phys. Discuss., 9, 18621-18657, 2009, http://www.atmos-chem-phys-discuss.net/9/18621/2009/.

Coheur, P.-F., Herbin, H., Clerbaux, C., Hurtmans, D., Wespes, C., Carleer, M., Turquety, S., Rinsland, C. P., Remedios, J., Hauglustaine, D., Boone, C. D., and Bernath, P. F.: ACE-FTS observation of a young biomass burning plume: first reported measurements of $\mathrm{C}_{2} \mathrm{H}_{4}, \mathrm{C}_{3} \mathrm{H}_{6} \mathrm{O}, \mathrm{H}_{2} \mathrm{CO}$ and PAN by infrared occultation from space, Atmos. Chem. Phys., 7, 5437-5446, 2007, http://www.atmos-chem-phys.net/7/5437/2007/.

Emanuel, K. A.: A scheme for representing cumulus convection in large-scale models, J. Atmos. Sci., 48, 2313-2335, 1991.

Freitas, S. R., Longo, K. M., Chatfield, R., Latham, D., Silva Dias, M. A. F., Andreae, M. O., Prins, E., Santos, J. C., Gielow, R., and Carvalho Jr., J. A.: Including the sub-grid scale plume rise of vegetation fires in low resolution atmospheric transport models, Atmos. Chem. Phys., 7, 3385-3398, 2007, http://www.atmos-chem-phys.net/7/3385/2007/. 
Fromm, M. D. and Servranckx, R.: Transport of forest fire smoke above the tropopause by supercell convection, Geophys. Res. Lett., 30(10), 1542, doi:10.1029/2002GL016820, 2002.

Giglio, L.: Characterization of the tropical diurnal fire cycle using VIRS and MODIS observations, Remote Sens. Environ., 108(4), 407-421, 2007.

Guan, H., Chatfield, R. B., Freitas, S. R., Bergstrom, R. W., and Longo, K. M.: Modeling the effect of plume-rise on the transport of carbon monoxide over Africa with NCAR CAM, Atmos. Chem. Phys., 8, 6801-6812, 2008,

http://www.atmos-chem-phys.net/8/6801/2008/.

Herzog, M., Graf, H.-F., Textor, C., and Oberhuber, J. M.: The effect of phase changes of water on the development of volcanic plumes, J. Volcanol. Geotherm. Res., 87, 55-74, 1998.

Hourdin, F., Couvreux, F., and Menut, L.: Parameterisation of the dry convective boundary layer based on a mass flux representation of thermals, J. Atmos. Sci., 59, 1105-1123, 2002.

Hourdin, F., Musat, I., Bony, S., Braconnot, P., Codron, F., Dufresne, J.-L., Fairhead, L., Filiberti, M.-A., Friedlingstein, P., Grandpeix, J.-Y., Krinner, G., LeVan, P., Li, Z.-X., and Lott, F.: The LMDZ4 general circulation model: climate performance and sensitivity to parametrized physics with emphasis on tropical convection , Clim. Dynam., 27, 787-813, 2006.

Jost, H.-J., Drdla, K., Stohl, A., et al.: In-situ observations of mid-latitude forest fire plumes deep in the stratosphere, Geophys. Res. Lett., 31, L11101, doi:10.1029/2003GL019253, 2004.

Justice, C. O., Giglio, L., Korontzi, S., Owens, J., Morisette, J. T., Roy, D., Descloitres, J., Alleaume, S., Petitcolin, F., and Kaufman, Y.: The MODIS fire products, Remote Sens. Environ., 83, 244-262, 2002.

Kahn, R. A., Li, W.-H., Moroney, C., Diner, D. J., Martonchik, J. V., and Fishbein, E.: Aerosol source plume physical characteristics from space-based multiangle imaging, J. Geophys. Res., 112, D11205, doi:10.1029/2006JD007647, 2007.

Kaiser, J. W., Hollingsworth, A., Calvet, J.-C., Leroy, M., Tinz, M., and Desaubies, Y.: Harmonised coordination of atmosphere, land, and ocean ("HALO") integrated projects of the GMES backbone, HALO report is available on: http://www.ecmwf.int/ research/EU_projects/HALO/docs_public.html, 2009.

Korontzi, S., Justice, C. O., and Scholes, R. J.: Influence of timing ans spatial extent of savanna fires in southern Africa on atmospheric emissions, J. Arid Environ., 54, 395-404, 2003.

Liousse, C., Guillaume, B., Grëgoire, J. M., Mallet, M., Galy, C., Pont, V., Akpo, A., Bedou, M., Castéra, P., Dungall, L., Gardrat, E., Granier, C., Konaré, A., Malavelle, F., Mariscal, A., Mieville, A., Rosset, R., Serça, D., Solmon, F., Tummon, F., Assamoi, E., Yoboué, V., and Van Velthoven, P.: Western african aerosols modelling with updated biomass burning emission inventories in the frame of the AMMA-IDAF program, Atmos. Chem. Phys. Discuss., 10, 7347-7382, 2010,

http://www.atmos-chem-phys-discuss.net/10/7347/2010/.

Louis, J.-F.: A parametric model of vertical eddy fluxes in the atmosphere., Bound.-Lay. Meteorol., 17, 187-202, 1979.

Luderer, G., Trentmann, J., Winterrath, T., Textor, C., Herzog, M., Graf, H. F., and Andreae, M. O.: Modeling of biomass smoke injection into the lower stratosphere by a large forest fire (Part II): sensitivity studies, Atmos. Chem. Phys., 6, 5261-5277, 2006, http://www.atmos-chem-phys.net/6/5261/2006/.
Mieville, A., Granier, C., Liousse, C., Guillaume, B., Mouillot, F., Lamarque, J.-F., Grégoire, J.-M., and Pétron, G.: Emissions of gases and particles from biomass burning during the 20th century using satellite data and an historical reconstruction, Atmos. Environ., accepted, 2009.

Morcrette, J. J.: Sur la paramétrisation du rayonnement dans les modèles de la circulation générale atmosphérique, thèse de Doctorat d'Etat, Univ. des Sci. et Tech. de Lille, France, 1984.

Oberhuber, J. M., Herzog, M., Graf, H.-F., and Schwanke, K.: Volcanic plumensimulation on large scales, J. Volcanol. Geotherm. Res., 87, 29-53, 1998.

Rio, C. and Hourdin, F.: A thermal plume model for the convective boundary layer: Representation of cumulus clouds, J. Atmos. Sci., 65, 407-425, 2008.

Schultz, M. G., Wooster, M., Boucher, O., Doutriaux-Boucher, M., Granier, C., Heil, A., Hollingsworth, A., Kaiser, J. W., Kasikowski, T., Morcrette, J.-J., Roberts, G., Simmons A., and van der Werf, G.: FREEVAL Evaluation of a Fire Radiative Power Product derived from Meteosat 8/9 and identification of operational user needs. Final Report: EUMETSAT Contract EUM/CO/06/4600000277/YG. Forschungszentrum Jülich GmbH, Jülich, Germany, ISBN:978-3-89336-549-4, 2009.

Siebesma, A. and Holtslag, A.: Model impacts of entrainment and detrainment rates in shallow cumulus convection, J. Atmos. Sci., 53, 2354-2364, 1996.

Stocks, B. J. and Flannigan, M. D.: Analysis of the behavior and associated weather for a 1986 northwestern Ontario wildfire: Red Lake No. 7, paper presented at the 9th Conference on Fire and Forest Meteorology, Am. Meteorol. Soc., San Diego, 2124 April, 1987.

Stocks, B. J., van Wilgen, B. W., Trollope, W. S. W., McRae, D. J., Mason, J. A., Weirich, F., and Potgieter, A. L. F.: Fuels and fire behavior dynamics on large-scale savanna fires in Kruger National Park, South Africa, J. Geophys. Res., 101, 23541-23550, doi:10.1029/95JD01734, 1996.

Tansey, K., Grégoire, J.-M., Defourny, P., Leigh, R., Pekel, J., Van Bogaert, E., and Bartholomé, E.: A new, global, multiannual (2000-2007) burnt area product at $1 \mathrm{~km}$ resolution, Geophys. Res. Lett., 35, L01401, doi:10.1029/2007GL031567, 2008.

Tiedtke, M.: A comprehensive mass flux scheme for cumulus parameterization in large-scale models, Mon. Weather Rev., 117, 1179-1800, 1989.

Trentmann, J., Andreae, M. O., Graf, H.-F., Hobbs, P. V., and Ottmar, R. D.: Simulation of a biomass-burning plume: Comparison of model results with observations, J. Geophys. Res., 107, 4013, doi:10.1029/2001JD000410, 2002.

Trentmann, J., Luderer, G., Winterrath, T., Fromm, M. D., Servranckx, R., Textor, C., Herzog, M., Graf, H.-F., and Andreae, M. O.: Modeling of biomass smoke injection into the lower stratosphere by a large forest fire (Part I): reference simulation, Atmos. Chem. Phys., 6, 5247-5260, 2006, http://www.atmos-chem-phys.net/6/5247/2006/.

van der Werf, G. R., Randerson, J. T., Giglio, L., Collatz, G. J., Kasibhatla, P. S., and Arellano Jr., A. F.: Interannual variability in global biomass burning emissions from 1997 to 2004, Atmos. Chem. Phys., 6, 3423-3441, 2006, http://www.atmos-chem-phys.net/6/3423/2006/. 
Wooster, M. J., Roberts, G., and Perry, G. L. W.: Retrieval of biomass combustion rates and totals from fire radiative power observations: FRP derivation and calibration relationships between biomass consumption and fire radiative energy release, J. Geophys. Res., 110, D24311, doi:10.1029/2005JD006318, 2005. 